\title{
Stereotactic body radiation therapy for prostate cancer: systematic review and meta-analysis of prospective trials
}

\author{
Taylor R. Cushman ${ }^{1}$, Vivek Verma², Rahul Khairnar ${ }^{3}$, Joseph Levy ${ }^{3}$, Charles B. \\ Simone 2nd ${ }^{4}$ and Mark V. Mishra ${ }^{4}$ \\ ${ }^{1}$ Department of Radiation Oncology, University of Texas M.D. Anderson Cancer Center, Houston, TX, USA \\ ${ }^{2}$ Department of Radiation Oncology, Allegheny General Hospital, Pittsburgh, PA, USA \\ ${ }^{3}$ Department of Health Policy and Management, Johns Hopkins Bloomberg School of Public Health, Baltimore, MD, USA \\ ${ }^{4}$ Department of Radiation Oncology, University of Maryland School of Medicine, Baltimore, MD, USA \\ Correspondence to: Vivek Verma, email: vivek333@gmail.com \\ Keywords: prostate cancer; stereotactic body radiation therapy; stereotactic ablative radiation therapy; hypofractionation; toxicities \\ Received: April 17, $2019 \quad$ Accepted: August 05, $2019 \quad$ Published: September 24, 2019 \\ Copyright: Cushman et al. This is an open-access article distributed under the terms of the Creative Commons Attribution License \\ 3.0 (CC BY 3.0), which permits unrestricted use, distribution, and reproduction in any medium, provided the original author and \\ source are credited.
}

\section{ABSTRACT}

Background: Despite the increasing worldwide utilization of stereotactic body radiation therapy (SBRT) for prostate cancer, there are no known summative data regarding its safety and efficacy. To address this knowledge gap, we conducted a PRISMA-guided systematic review and meta-analysis of prospective prostate SBRT trials.

Results: Fourteen trials with a total of 2,038 patients were included. Median follow-up was 37 months (range 6-55 months). Most patients had CT1-T2a, Gleason $\leq 7$ disease with median pre-treatment PSAs of 5-10; 1,042 (51\%) were low-risk, $744(37 \%)$ were intermediate-risk, $158(8 \%)$ were high-risk, and the remainder were unreported. Doses ranged from 33.5-50.0 Gy, most typically in 5 fractions, with nearly all studies delivering nondaily fractionation with some type of daily image guidance. Outcomes were converted into counts at the end of one year. The pooled rate of FFBF was $98 \%$ [95\% confidence interval, 97-98\%]. The pooled rate of late grade $\geq 3$ gastrointestinal and genitourinary toxicities were $1 \%[0-5 \%]$ and $2 \%$ [1-3\%], respectively.

Methods: PubMed and Google Scholar were queried for prospective studies evaluating survival and/or toxicity outcomes in SBRT ( $\leq 5$ fractions) for localized prostate cancer. Pooled rates of freedom from biochemical failure (FFBF) and late grades $\geq 3$ gastrointestinal (GI) and genitourinary (GU) toxicities were assessed. Metaanalysis of proportions was logit transformed and pooled using generalized linear mixed models (both fixed and random effects) and subsequently back transformed to standard proportions.

Conclusions: Despite the lack of long-term follow-up and heterogeneity of the available evidence, prostate SBRT affords appropriate biochemical control with few high-grade toxicities. These data have implications for ongoing worldwide utilization of prostate SBRT as well as ongoing prospective investigations.

\section{INTRODUCTION}

External beam radiation therapy (EBRT) for localized, non-metastatic prostate cancer (PC) has historically been delivered with conventionally fractionated doses of 1.8-2.0 Gy per fraction generally over the course of 40-44 treatments. However, given the inconvenience of this regimen for patients and 
concerns regarding the low $\alpha / \beta$ ratio of $\mathrm{PC}[1-4]$, prostate hypofractionation (most commonly 2.5-3.4 Gy per fraction) has come into better focus over the last decade, especially with the publication of randomized trials such as Radiation Therapy Oncology Group (RTOG) 0415, CHHIP, HYPRO, and PROFIT [5-8].

In addition to these encouraging phase III data, together with the expansion of technologies such as image guidance platforms, stereotactic body radiation therapy (SBRT) has become a highly active area of ongoing research for localized prostate cancer. SBRT also capitalizes on the low $\alpha / \beta$ ratio of $\mathrm{PC}$ and involves fractional doses even higher than hypofractionation. It is typically delivered in 5 or fewer fractions and allows for high target conformality in conjunction with highquality image guidance. Dosimetric data even suggest that SBRT may be dosimetrically closer to high-dose-rate brachytherapy than non-stereotactic EBRT [9, 10].

Although the adoption of prostate hypofractionation is rapidly rising (and expected to expand even further in the future), there are few existing prospective experiences for SBRT, including no published phase III trials. In 2013, despite the limited data, the American Society for Radiation Oncology (ASTRO) listed SBRT as an alternative for low- and intermediate-risk PC [11]. The recently published guidelines from the American Urological Association, ASTRO, and the Society of Urologic Oncology also remain vague regarding the evidence-based utility of SBRT for PC [12].

However, in the absence of completed randomized trials, summative data are urgently needed in order to better evaluate the safety and efficacy of prostate SBRT. Hence, the goal of this work, the first of its kind to date, was to perform a systematic review and meta-analysis of prospective trials for prostate SBRT in PC.

\section{RESULTS}

Supplementary Figure 1 displays a flow diagram of study selection. The initial search identified 612 studies, of which 24 were retrieved for full text review. Of those, 14 met the criteria of a prospective trial investigating survival and/or toxicity of SBRT in PC [15-32]. Publication year ranged from 2007 to 2017, and sample sizes ranged from 15 to 1,100 patients.

A summary of the study populations of the selected studies is displayed in Table 1. Of 2,038 total patients, 1,042 (51\%) were low-risk, 744 (37\%) intermediate-risk, and 158 (8\%) high-risk; 91 (4\%) did not have specific risk groups reported. Most patients had cT1-T2a, Gleason $\leq 7$ disease with median pre-treatment prostate-specific antigen (PSA) values between 5 and 10 .

Table 2 summarizes treatment-related parameters. The SBRT dose ranged from 33.5-50.0 Gy and was typically delivered in nondaily regimens. Image guidance was used in some capacity in all studies; although three did not report specific platforms, five studies utilized CyberKnife orthogonal radiography, five used cone-beam computed tomography (CT), and one utilized megavoltage CT. Eight studies allowed the use of androgen deprivation therapy (ADT) (nearly always $\leq 9$ months). Only one study reported treatment of lymph nodes (which was hypofractionated) [26]. Management of rectal filling was incompletely reported by most studies.

A summary of outcomes is given in Table 3. Of the studies that documented a post-SBRT PSA nadir, most $(75 \%)$ reported values of 0.5 or less. The mean and median follow-up of each study was 35 and 37 months, respectively. Using a random effects model, the pooled rate of FFBF at one year was 98\% [95\% confidence interval (CI), 97-98\%] (Figure 1). Toxicities were reported using the Common Terminology Criteria for Adverse Events (CTCAE) for 8 studies, whereas 5 studies used RTOG methodology and one study did not report the method. Pooled late grade $\geq 3$ gastrointestinal (GI) toxicity was $1 \%$ [95\% CI, 0-5\%] (Figure 2), and late grade $\geq 3$ genitourinary $(\mathrm{GU})$ toxicity was $2 \%$ [95\% CI, 1-3\%] (Figure 3). Nearly every study grouped both early and late adverse events; therefore, sub-analysis based on these factors could not be performed. Although quality of life parameters and measurements were highly heterogeneous, many studies reported a decline following SBRT that improved thereafter.

\section{DISCUSSION}

This systematic review and meta-analysis addresses a major knowledge gap and demonstrates that prostate SBRT produces appropriate biochemical control outcomes with few high-grade toxicities. However, these data should be interpreted with caution for several reasons, chiefly owing to the lack of long-term follow-up and heterogeneity of the available evidence. Nevertheless, this study has implications for ongoing utilization of prostate SBRT across the world as well as ongoing prospective trials.

There are several seminal conventional fractionation trials to which these data may be roughly compared, although available follow-up times remain a hindrance to interpretation. In a sentinel phase 3 trial of doseescalation, Zietman and colleagues reported comparable toxicity outcomes and 10-year biochemical failure rates of $7.1 \%$ and $30.4 \%$ in low- and intermediate risk patients who received high-dose RT (79.2 Gy) [33]. The M. D. Anderson dose-escalation trial reported freedom from biochemical or clinical failure of $88 \%$ and $86 \%$ at 8 years in low- and intermediate risk patients in the doseescalated (78 Gy) RT cohort, respectively [34]. Reported 10-year incidence of grade $3 \mathrm{GI}$ and GU toxicities were $7 \%$ and $4 \%$, respectively. Neither of these studies utilized contemporary image guidance or included ADT, and of note, the role of ADT in the setting of prostate SBRT for various risk groups is currently unknown. Nevertheless, the 
Table 1: Summary of patient populations of the selected studies

\begin{tabular}{|c|c|c|c|c|c|c|}
\hline Reference, Year & $\begin{array}{l}\text { Sample } \\
\text { Size }\end{array}$ & $\begin{array}{c}\text { Risk Group } \\
\text { Stratification } \\
\text { (LR, IR, HR) }\end{array}$ & T Stage & $\begin{array}{l}\text { Median pre- } \\
\text { SBRT PSA }\end{array}$ & Gleason Grade & $\begin{array}{c}\text { Baseline } \\
\text { Symptoms or IPSS }\end{array}$ \\
\hline Quon, 2018 & 152 & $20,129,0$ & $\begin{array}{c}1(98), 2 \mathrm{a}(36) \\
2 \mathrm{~b}(17)\end{array}$ & $\begin{array}{l}7.2(5.5-11.3) \\
8.2(6.2-12.7)\end{array}$ & $\begin{array}{c}6(30) \\
7(121)\end{array}$ & $7(3-12), 4(2-9)$ \\
\hline Boyer, 2017 & 60 & $20,40,0$ & $\begin{array}{c}1 \mathrm{c}(47), 2 \mathrm{a}(11) \\
2 \mathrm{~b}(2)\end{array}$ & 5.83 & $6(24), 7(36)$ & $\begin{array}{l}\text { AUASS (4.5), } \\
\text { EPIC (94.4) }\end{array}$ \\
\hline Hannan, 2016 & 91 & $33,58,0$ & $\begin{array}{c}\text { 1c (63), } 2 \mathrm{a}(20), \\
2 \mathrm{~b}(8)\end{array}$ & 6.4 & $\begin{array}{c}6(43), 3+4(33), 4+3 \\
(15)\end{array}$ & AUASS (5) \\
\hline Rucinska, 2016 & 68 & $7,61,0$ & $\begin{array}{c}1 \mathrm{c}(6), 2 \mathrm{a}(15), 2 \mathrm{~b} \\
(19), 2 \mathrm{c}(28)\end{array}$ & 10 & $\begin{array}{c}3(2), 5(21), 6(14), 7 \\
(29), 8(2)\end{array}$ & NR \\
\hline Shikama, 2016 & 20 & $12,8,0$ & $\begin{array}{c}1 \mathrm{c}(16), 2 \mathrm{a}(2), 2 \mathrm{~b} \\
(1), 2 \mathrm{c}(1)\end{array}$ & 6.9 & $\begin{array}{c}6(14), 3+4(3), 4+3 \\
(3)\end{array}$ & $\begin{array}{l}\text { IPSS scores: } 0-5 \\
(12), 6-10(4) \\
11-16(4)\end{array}$ \\
\hline $\begin{array}{l}\text { D'Agostino, } \\
2016\end{array}$ & 90 & $53,37,0$ & NR & 6.9 & $6(58), 7(32)$ & NR \\
\hline Bauman, 2015 & 15 & $0,0,15$ & $2(11), 3(5)$ & 27.4 & $7(9), 8-10(6)$ & NR \\
\hline Bernetich, 2014 & 142 & $61,63,18$ & $\begin{array}{c}1 \mathrm{c}(106), 2 \mathrm{a}(19), \\
>2 \mathrm{a}(17)\end{array}$ & 5.7 & $\begin{array}{c}5-6(76), 7(54), 8+ \\
(12)\end{array}$ & NR \\
\hline Kim, 2014 & 91 & - & $\begin{array}{c}1 \mathrm{c}(32), 2 \mathrm{a}(7) \\
2 \mathrm{~b}(6)\end{array}$ & 5.6 & $\begin{array}{c}6(21), 3+4(16), 4+3 \\
(8)\end{array}$ & NR \\
\hline King, 2013 & 1100 & $641,334,125$ & NR & NR & NR & $\begin{array}{l}\text { Median EPIC } \\
\text { urinary score } 89\end{array}$ \\
\hline Loblaw, 2013 & 84 & $84,0,0$ & $\begin{array}{l}1 \mathrm{a}(1), 1 \mathrm{c}(77), \\
2 \mathrm{a}(6)\end{array}$ & 5.3 & 6 for all & NR \\
\hline Alongi, 2013 & 40 & $26,14,0$ & NR & 6.25 & 6 (median) & IPSS 0-7 \\
\hline McBride, 2011 & 45 & $45,0,0$ & 1c (33), 2a (12) & 4.9 & $6(45)$ & NR \\
\hline Madsen, 2007 & 40 & $40,0,0$ & NR & 5.0 & $<7$ for all & Median AUA 13 \\
\hline
\end{tabular}

Abbreviations: NR, not reported; LR, low-risk; IR, intermediate-risk; HR, high-risk; SBRT, stereotactic body radiation therapy; PSA, prostate-specific antigen; IPSS, International Prostate Symptom Score; AUASS; American Urologic Association Symptom Score; EPIC, Expanded Prostate Cancer Index.

Table 2: Summary of treatment parameters of the selected studies

\begin{tabular}{|c|c|c|c|c|c|c|}
\hline Reference, Year & $\begin{array}{l}\text { Sample } \\
\text { Size }\end{array}$ & $\begin{array}{c}\text { SBRT Dose, } \\
\text { Fractionation, } \\
\text { Timing }\end{array}$ & $\begin{array}{c}\text { Image } \\
\text { Guidance }\end{array}$ & ADT & $\begin{array}{c}\text { LN } \\
\text { Treatment }\end{array}$ & $\begin{array}{c}\text { Rectal } \\
\text { Management }\end{array}$ \\
\hline Quon, 2018 & 152 & $\begin{array}{l}40, \mathrm{q} 7 \mathrm{~d} \\
40, \mathrm{q} 2 \mathrm{~d}\end{array}$ & CBCT & $<6$ months & NR & NR \\
\hline Boyer, 2017 & 60 & $37.5,5, \mathrm{q} 2 \mathrm{~d}$ & CBCT & None & None & $\begin{array}{l}\text { Milk of Mg, fleet } \\
\text { enema }\end{array}$ \\
\hline Hannan, 2016 & 91 & $33.5,5, \mathrm{q} 2 \mathrm{~d}$ & NR & $<9$ months & None & NR \\
\hline Rucinska, 2016 & 68 & $33.5,5, \mathrm{q} 3 \mathrm{~d}$ & MVCT & $\begin{array}{c}\text { Yes, } \\
\text { unspecified }\end{array}$ & None & NR \\
\hline Shikama, 2016 & 20 & $35,5, \mathrm{q} 2 \mathrm{~d}$ & CyberKnife & $\leq 8$ months & NR & NR \\
\hline D’Agostino, 2016 & 90 & $35,5, \mathrm{q} 2 \mathrm{~d}$ & CBCT & $\leq 6$ months & NR & NR \\
\hline Bauman, 2015 & 15 & $40,5, \mathrm{q} 1 \mathrm{w}$ & CBCT & $\leq 12$ months & $25 \mathrm{~Gy}$ in $5 \mathrm{fx}$ & NR \\
\hline Bernetich, 2014 & 142 & $\begin{array}{c}35 / 36.25 / 37,5 \\
q 2 d\end{array}$ & CyberKnife & None & NR & NR \\
\hline Kim, 2014 & 91 & $45 / 47.5 / 50,5, \mathrm{q} 7 \mathrm{~d}$ & CyberKnife & NR & NR & $\begin{array}{l}\text { Milk of } \mathrm{Mg}+ \\
\text { rectal balloon }\end{array}$ \\
\hline
\end{tabular}




\begin{tabular}{lcccccc} 
King, 2013 & 1100 & $35-40,5, \mathrm{qd}$ & Cyberknife & $\leq 3$ months & None & NR \\
Loblaw, 2013 & 84 & $35,5, \mathrm{q} 1 \mathrm{w}$ & $\mathrm{NR}$ & 4 months & NR & NR \\
Alongi, 2013 & 40 & $35,5, \mathrm{q} 2 \mathrm{~d}$ & $\mathrm{CBCT}$ & $\begin{array}{c}\text { Per NCCN } \\
\text { guidelines }\end{array}$ & NR & $\begin{array}{c}\text { SpaceOAR } \\
\text { hydrogel } \\
\text { Yes, unspecified }\end{array}$ \\
McBride, 2011 & 45 & $36.3-37.5,5, \mathrm{qd}$ & CyberKnife & None & NR & NR \\
Madsen, 2007 & 40 & $33.5,5, \mathrm{qd}$ & NR & NR & NR \\
\hline
\end{tabular}

Abbreviations: NR, not reported; SBRT, stereotactic body radiation therapy; ADT, androgen deprivation therapy; LN, lymph node; CBCT, cone-beam computed tomography; Mg; magnesia; MVCT, megavoltage computed tomography; Gy, Gray; fx, fractions; NCCN, National Comprehensive Cancer Network.

Table 3: Summary of outcomes of the selected studies

\begin{tabular}{|c|c|c|c|c|c|c|c|c|}
\hline $\begin{array}{l}\text { Reference, } \\
\text { Year }\end{array}$ & $\begin{array}{l}\text { Sample } \\
\text { Size }\end{array}$ & $\begin{array}{l}\text { Median } \\
\text { follow- } \\
\text { up (mo) }\end{array}$ & $\begin{array}{c}\operatorname{FFBF}^{*}(\% \\
\text { or median) }\end{array}$ & $\begin{array}{c}\text { PSA } \\
\text { Nadir }\end{array}$ & $\begin{array}{c}\text { Toxicity } \\
\text { Measurement } \\
\text { Method }\end{array}$ & $\begin{array}{l}\text { Late Grade } \\
\quad \geq \mathbf{3} \text { GI } \\
\text { Toxicity }(\%)\end{array}$ & $\begin{array}{l}\text { Late Grade } \\
\quad \geq 3 \text { GU } \\
\text { Toxicity }(\%)\end{array}$ & QOL Conclusions \\
\hline Quon, 2018 & 152 & 47 & NR & NR & RTOG & 4.07 & 9.4 & $\begin{array}{c}\text { Prostate SBRT delivered QW } \\
\text { improved acute bowel and urinary } \\
\text { QOL compared to treatment EOD. } \\
\text { Patients should be counselled } \\
\text { regarding the significant short-term } \\
\text { benefits of a longer overall treatment } \\
\text { time. }\end{array}$ \\
\hline Boyer, 2017 & 60 & 27.6 & NR & NR & CTCAE & 1.7 & 0 & $\begin{array}{c}\text { AUASS } 11 \text { during SBRT, and } 5 \text { at } 5 \\
\text { mo EPIC } 91.7 \text { and } 88.9 \text { at } 3 \text { and } 12 \\
\text { mo }\end{array}$ \\
\hline Hannan, 2016 & 91 & 54 & $\begin{array}{c}100 \% \text { at } 3 y \\
98.6 \% \text { at } \\
5 y\end{array}$ & 0.13 & RTOG & 6.8 & 5.5 & $\begin{array}{l}\text { No differences among dose levels for } \\
\text { EPIC or AUASS }\end{array}$ \\
\hline $\begin{array}{l}\text { Rucinska, } \\
2016\end{array}$ & 68 & 24 & $100 \%$ & 0.03 & RTOG & 0 & 0 & $\begin{array}{l}\text { GHS/QoL was "good" } 9 \text { mo post- } \\
\text { SBRT, significantly improved } \\
\text { thereafter }\end{array}$ \\
\hline Shikama, 2016 & 20 & 30 & $100 \%$ & 0.73 & CTCAE & 2.5 & 0 & NR \\
\hline $\begin{array}{l}\text { D'Agostino, } \\
2016\end{array}$ & 90 & 28 & $\begin{array}{l}97.8 \% \text { at } \\
27 \mathrm{mo}\end{array}$ & NR & CTCAE & 0 & 0 & NR \\
\hline Bauman, 2015 & 15 & 6 & NR & 0.3 & CTCAE & 25 & $6.7 \%$ & NR \\
\hline $\begin{array}{l}\text { Bernetich, } \\
2014\end{array}$ & 142 & 38 & $\begin{array}{l}92.7 \% \text { at } \\
5 \text { years for } \\
\text { the entire } \\
\text { cohort }\end{array}$ & 0.16 & RTOG & 0 & 2 & NR \\
\hline Kim, 2014 & 91 & 42 & $99 \%$ & NR & CTCAE & 5.5 & NR & $\begin{array}{l}\text { EPIC bowel scores lower than } \\
\text { baseline } 18 \text { months post-SBRT }\end{array}$ \\
\hline King, 2013 & 1100 & 36 & $93 \%$ & 0.51 & NR & NR & NR & $\begin{array}{l}\text { Urinary and bowel QOL decline most } \\
\text { notable within the first } 3 \text { mo, mostly } \\
\text { recovered by } 6 \text { mo, stable thereafter, } \\
\text { improvement over baseline starting } \\
\text { at } 3 y\end{array}$ \\
\hline Loblaw, 2013 & 84 & 55 & $99.9 \%$ & NR & RTOG & 1 & 1 & $\begin{array}{l}\text { No significant decline in long-term } \\
\text { QOL }\end{array}$ \\
\hline Alongi, 2013 & 40 & 11 & NR & 0.2 & CTCAE & 0 & 0 & NR \\
\hline McBride, 2011 & 45 & 45 & NR & $<1$ & CTCAE & 0 & 2.5 & $\begin{array}{l}\text { Significant late decline in SHIM } \\
\text { and EPIC sexual scores, small, late } \\
\text { decline in EPIC bowel domain }\end{array}$ \\
\hline Madsen, 2007 & 40 & 41 & $90 \%$ & NR & CTCAE & 0 & 0 & NR \\
\hline
\end{tabular}

Abbreviations: NR, not reported; FFBF, actuarial freedom from biochemical failure; PSA, prostate-specific antigen; GI, gastrointestinal; GU, genitourinary; QOL, quality of life; CTCAE, Common Toxicity Criteria for Adverse Events; AUASS; American Urologic Association Symptom Score; SBRT, stereotactic body radiation therapy; EPIC, Expanded Prostate Cancer Index; RTOG, Radiation Therapy Oncology Group; GHS, global health score; LR, low-risk; IR, intermediate-risk; HR, high-risk; SHIM, Sexual Health Inventory in Men.

*All studies but one utilized the Phoenix definition of biochemical failure. 
figures herein also compare well to more contemporarily published randomized trials of hypofractionated RT; however, limiting interpretation is the variability between trials regarding ADT, seminal vesicle target coverage, and most importantly, image guidance [5-8]. Nevertheless, when interpreted conservatively, data on prostate SBRT do not display an overt decrease in outcomes or increase toxicities compared with these historical conventional fractionation trials.

Consideration of strategies to reduce toxicities remains an integral factor in the radiotherapeutic treatment of PC, regardless of modality/technique, but especially important for SBRT. Foremost is the use of high-quality image guidance; to this extent, the use of megavoltage CT is likely inadequate for prostate SBRT, and kilovoltage fan-beam CT provides higher-quality imaging than kilovoltage cone-beam CT. Additionally, the vast majority of studies did not specifically report the degree of seminal vesicle target coverage or the methods for rectal management. As such, positive experiences with hydrogel rectal spacers in the conventionally fractionated setting may prove to be especially useful for prostate SBRT [35]. Additionally, nondaily fractionation regimens, seen in many of the studies included in analysis, may play a role in reduced toxicity [36]. One prospective trial used a unique fractionation delivery scheme of one fraction a week for eight weeks to 43.8-45.2 Gy [24] and reported no acute or late grade 33 GI or GU toxicities, suggesting

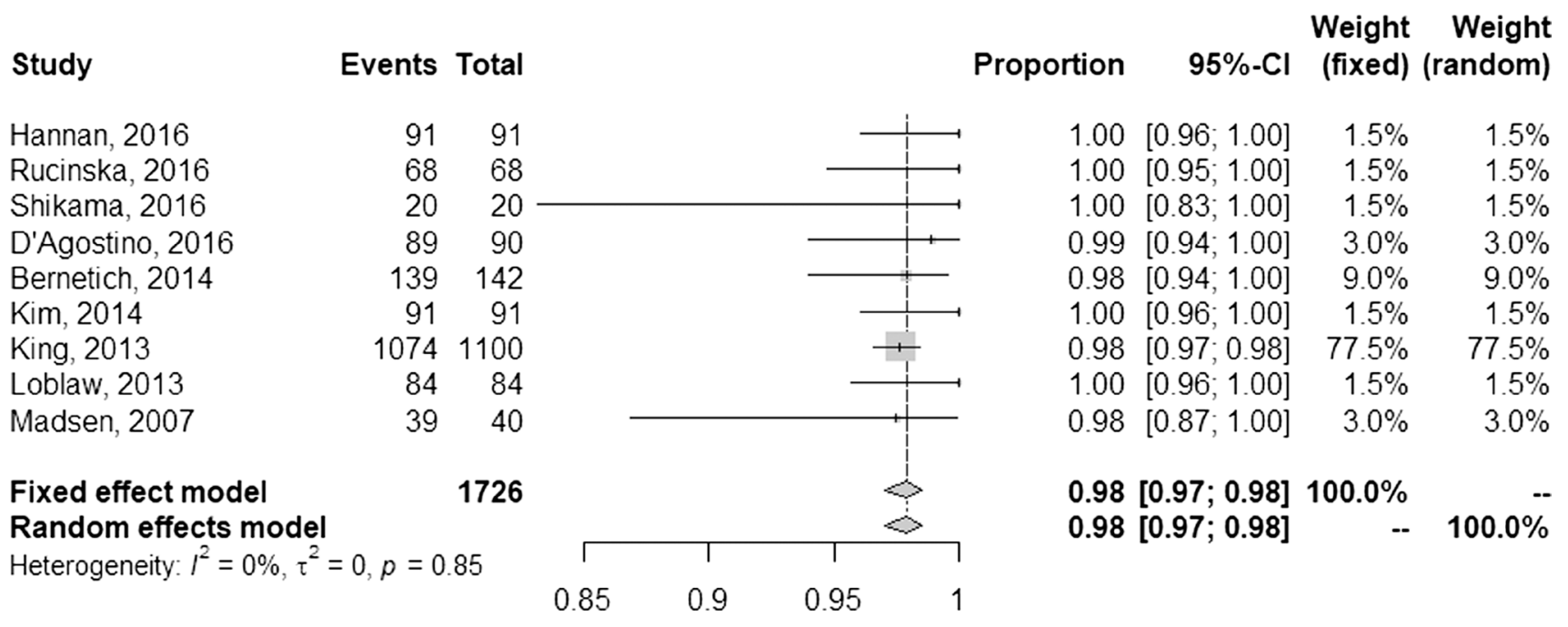

Figure 1: Pooled and individual rates of freedom from biochemical failure.

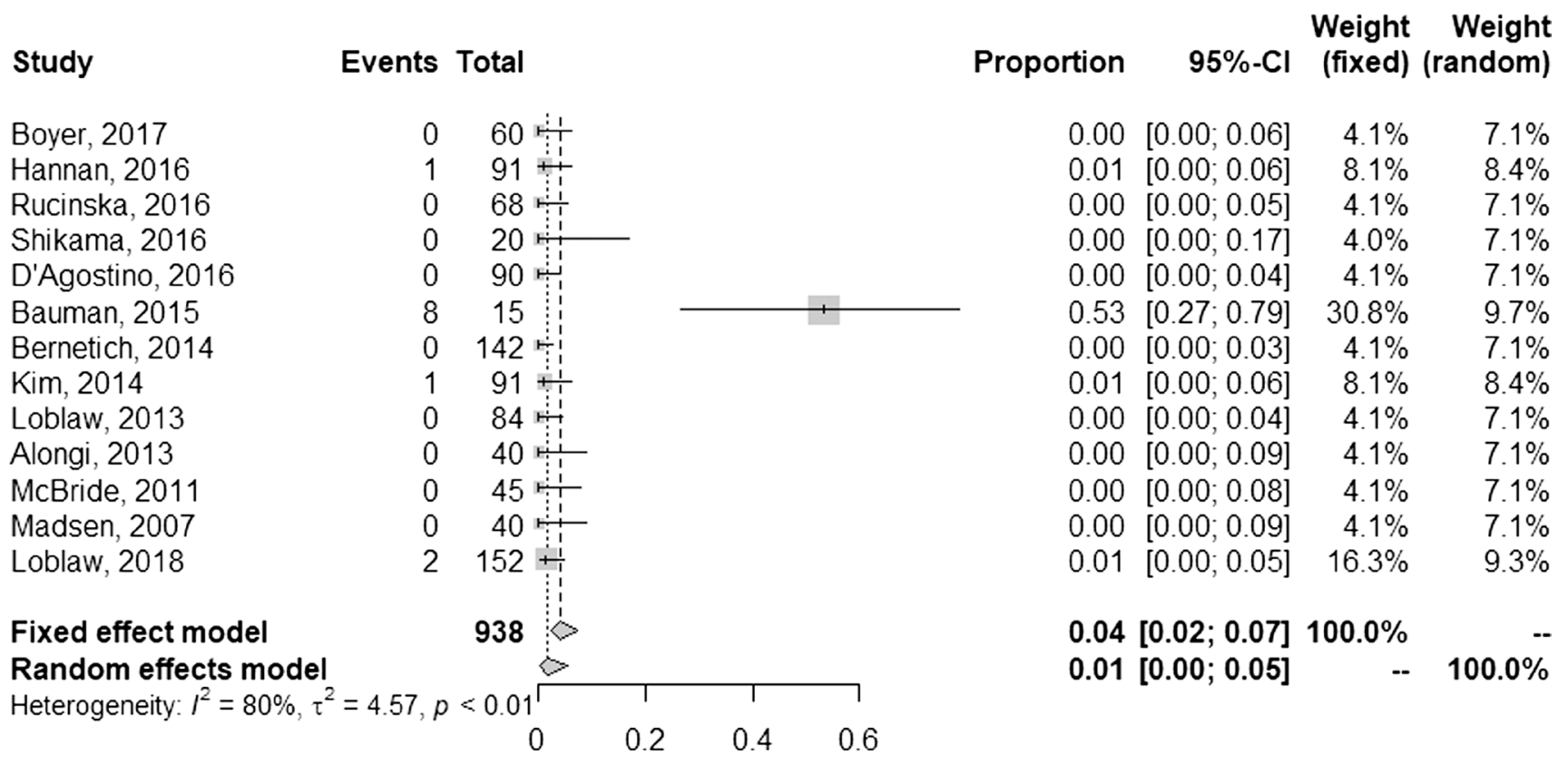

Figure 2: Pooled and individual rates of late grade $\geq 3$ gastrointestinal toxicities. 
that an intermediate dose/fractionation scheme could be a satisfactory strategy for minimizing adverse events. Other considerations to reduce toxicities include ADT to reduce prostate volume prior to SBRT as well as more stringent selection of patients having undergone prior transurethral resection of the prostate.

Although this study is the largest investigation of SBRT for PC to date, the role of SBRT for PC will be better addressed with the eventual publication of multiple ongoing randomized trials. For instance, the international phase III Prostate Advances in Comparative Evidence (PACE) trial (NCT01584258) compares laparoscopic prostatectomy to SBRT and conventional RT or SBRT alone in patients with early-stage PC. Additionally, the HYPO-RT-PC trial (ISRCTN45905321) aims to compare the safety and efficacy of hypofractionated RT in intermediate-risk PC. Preliminary results display comparable late toxicity and favorable early toxicity of SBRT over standard fractionation [37]. However, it is important to note that this study utilizes seven fractions of 6.1 Gy each, and therefore would not meet the definition of SBRT ( $\leq 5$ fractions) used in the current analysis.

The chief limitation of this work is the lack of long-term follow-up data in the analyzed trials; just two investigations herein reported median follow-up times approaching 5 years $[15,30]$. Second, there are several sources of heterogeneity from study to study that are worth mentioning. For instance, there was a nearly even split in toxicity reporting based on ASTRO versus CTCAE criteria; research has highlighted the influence of reporting methodologies on differences in reported toxicity outcomes [38]. There were also various dose/fractionation schemes, baseline patient/disease characteristics, technical aspects of SBRT delivery, and image guidance capabilities. Prostate volume was also not discussed in nearly all studies, which may be an important determinant of toxicities [39]. Third, additional limitations of the analysis include the lack of individual patient data, as well as the fact that one study provided slightly over half the patients in this entire meta-analysis [20]. Moreover, as with any prospective study, the presence of enrollment bias may result in patients at higher risk of toxicities potentially not having been offered enrollment on protocol. Nevertheless, in light of these shortcomings, we encourage conservative interpretation of these data, while recognizing the necessity of long-term follow-up data.

\section{MATERIALS AND METHODS}

\section{Systematic review}

The systematic review was conducted using the Preferred Reporting Items for Systematic Review and Meta-Analyses [13] guidelines [13]. Eligibility criteria included prospective studies evaluating survival and/or toxicity outcomes with SBRT (defined as $\leq 5$ fractions, the most common definition of SBRT used in the studies assessed) for non-metastatic PC.

The PubMed and Google Scholar search engines were queried for terms "stereotactic" or "SBRT" or "SABR" and "radiation" or "radiotherapy" and "prostate." A broad keyword search was deliberately performed so as not to inadvertently exclude potentially relevant publications. Other data sources were publications known to the authors as well as those cited in relevant articles. In efforts to analyze only higher-quality evidence, only prospective trials were included; unpublished data were

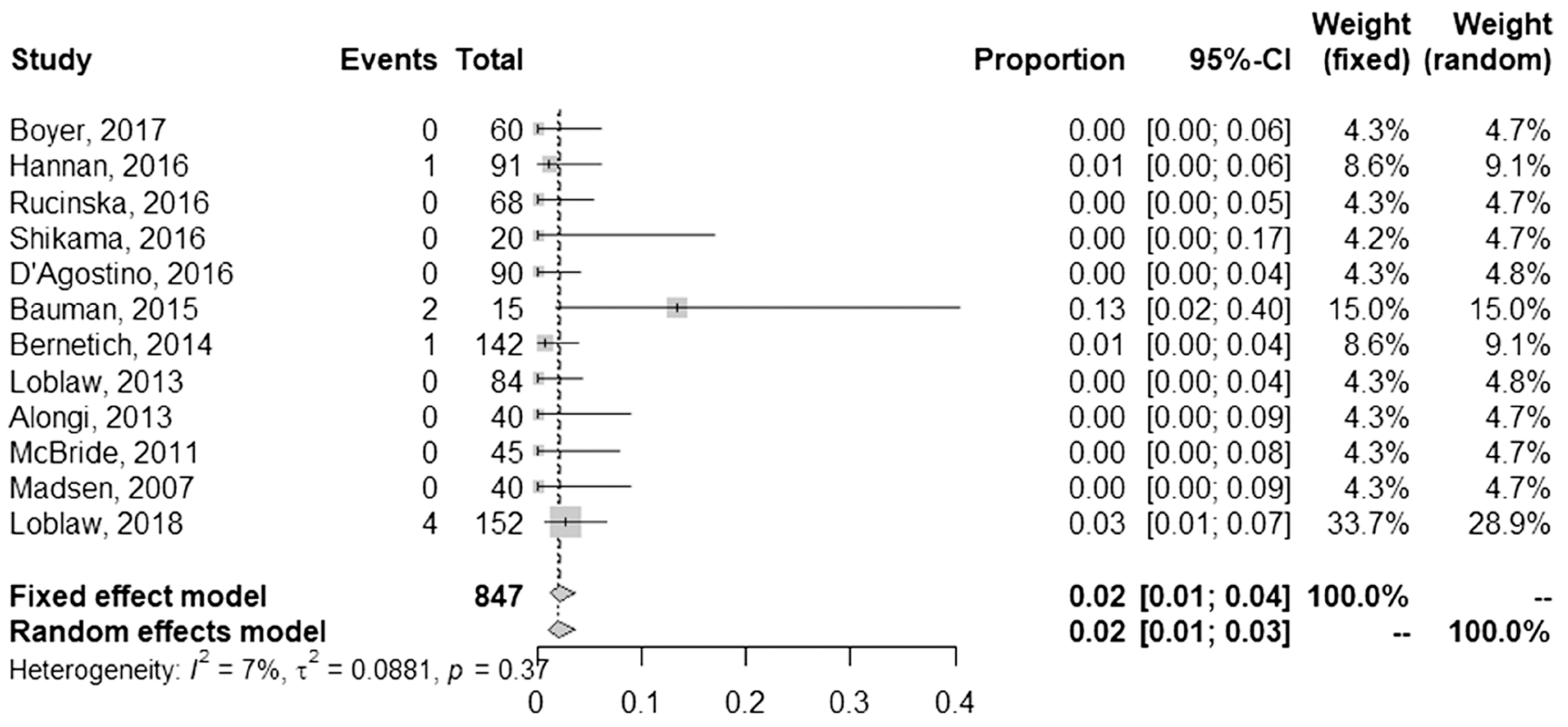

Figure 3: Pooled and individual rates of late grade $\geq 3$ genitourinary toxicities. 
not included owing to the inability to verify methodology and validity. Care was taken to ensure that cohorts reported at multiple timepoints were not included more than once to avoid weighting bias; if there was overlap between publications from the same group, the most recent publication was utilized. Systematic searches were conducted by two independent authors. Date restrictions were not utilized and included all eligible articles published through January 1, 2018.

\section{Meta-analysis}

For meta-analysis of proportions, data was logit transformed then pooled using an inverse variance methodology (both fixed and random effects), then backtransformed to standard proportions. Separate analyses were performed for the three main outcomes of the study: freedom from biochemical failure (FFBF), late grade $\geq 3$ gastrointestinal (GI) toxicity, and late grade $\geq 3$ genitourinary (GU) toxicity. To combine outcomes with varying endpoints, variables reported at median followup for each study were converted into counts at the end of year one, with the assumption of constant rates of occurrence over time. All analyses were conducted in R using the 'metaprop' function of the R package 'metafor', which calculates the overall proportion from studies reporting single proportions [14].

\section{CONFLICTS OF INTEREST}

A portion of this work was presented at the 2018 Annual Meeting of the American Society for Radiation Oncology. Dr. Mark Mishra reports receiving an honorarium and travel from Varian. All other authors declare that conflicts of interest do not exist.

\section{FUNDING}

There were no funding sources for this study.

\section{REFERENCES}

1. Brenner DJ, Hall EJ. Fractionation and protraction for radiotherapy of prostate carcinoma. Int J Radiat Oncol Biol Phys. 1999; 43:1095-101. https://doi.org/10.1016/S03603016(98)00438-6. [PubMed]

2. Daşu A. Is the alpha/beta value for prostate tumours low enough to be safely used in clinical trials? Clin Oncol ( R Coll Radiol). 2007; 19:289-301. https://doi.org/10.1016/j. clon.2007.02.007. [PubMed]

3. Fowler J, Chappell R, Ritter M. Is alpha/beta for prostate tumors really low? Int J Radiat Oncol Biol Phys. 2001; 50:1021-31. https://doi.org/10.1016/S0360-3016(01)016078. [PubMed]

4. Friedland JL, Freeman DE, Masterson-McGary ME, Spellberg DM. Stereotactic body radiotherapy: an emerging treatment approach for localized prostate cancer. Technol Cancer Res Treat. 2009; 8:387-92. https://doi. org/10.1177/153303460900800509. [PubMed]

5. Lee WR, Dignam JJ, Amin MB, Bruner DW, Low D, Swanson GP, Shah AB, D'Souza DP, Michalski JM, Dayes IS, Seaward SA, Hall WA, Nguyen PL, et al. Randomized Phase III Noninferiority Study Comparing Two Radiotherapy Fractionation Schedules in Patients With Low-Risk Prostate Cancer. J Clin Oncol. 2016; 34:2325-32. https://doi.org/10.1200/JCO.2016.67.0448. [PubMed]

6. Dearnaley D, Syndikus I, Mossop H, Khoo V, Birtle A, Bloomfield D, Graham J, Kirkbride P, Logue J, Malik Z, Money-Kyrle J, O'Sullivan JM, Panades M, et al, and CHHiP Investigators. Conventional versus hypofractionated high-dose intensity-modulated radiotherapy for prostate cancer: 5-year outcomes of the randomised, non-inferiority, phase 3 CHHiP trial. Lancet Oncol. 2016; 17:1047-60. https://doi.org/10.1016/S1470-2045(16)30102-4. [PubMed]

7. Incrocci L, Wortel RC, Alemayehu WG, Aluwini S, Schimmel E, Krol S, van der Toorn PP, Jager H, Heemsbergen W, Heijmen B, Pos F. Hypofractionated versus conventionally fractionated radiotherapy for patients with localised prostate cancer (HYPRO): final efficacy results from a randomised, multicentre, open-label, phase 3 trial. Lancet Oncol. 2016; 17:1061-69. https://doi. org/10.1016/S1470-2045(16)30070-5. [PubMed]

8. Catton CN, Lukka H, Gu CS, Martin JM, Supiot S, Chung PW, Bauman GS, Bahary JP, Ahmed S, Cheung P, Tai KH, Wu JS, Parliament MB, et al. Randomized Trial of a Hypofractionated Radiation Regimen for the Treatment of Localized Prostate Cancer. J Clin Oncol. 2017; 35:1884-90. https://doi.org/10.1200/JCO.2016.71.7397. [PubMed]

9. Fuller DB, Naitoh J, Lee C, Hardy S, Jin H. Virtual HDRSM CyberKnife Treatment for Localized Prostatic Carcinoma: Dosimetry Comparison With HDR Brachytherapy and Preliminary Clinical Observations. Int J Radiat Oncol Biol Phys. 2008; 70:1588-97. https://doi.org/10.1016/j. ijrobp.2007.11.067. [PubMed]

10. Fukuda S, Seo Y, Shiomi H, Yamada Y, Ogata T, Morimoto M, Konishi K, Yoshioka Y, Ogawa K. Dosimetry analyses comparing high-dose-rate brachytherapy, administered as monotherapy for localized prostate cancer, with stereotactic body radiation therapy simulated using CyberKnife. J Radiat Res (Tokyo). 2014; 55:1114-21. https://doi. org/10.1093/jirr/rru048. [PubMed]

11. American Society for Radiation Oncology. Stereotactic Body Radiation Therapy. SBRT. 2013.

12. Sanda MG, Cadeddu JA, Kirkby E, Chen RC, Crispino T, Fontanarosa J, Freedland SJ, Greene K, Klotz LH, Makarov DV, Nelson JB, Rodrigues G, Sandler HM, et al. Clinically Localized Prostate Cancer: AUA/ASTRO/SUO Guideline. Part II: Recommended Approaches and Details of Specific Care Options. J Urol. 2018; 199:990-97. https://doi. org/10.1016/j.juro.2018.01.002. [PubMed]

13. Moher D, Liberati A, Tetzlaff J, Altman DG, and PRISMA Group. Preferred reporting items for systematic reviews 
and meta-analyses: the PRISMA statement. Int J Surg. 2010; 8:336-41. https://doi.org/10.1016/j.ijsu.2010.02.007. [PubMed]

14. Viechtbauer W. Conducting Meta-Analyses in $\mathrm{R}$ with metafor Package. J Stat Softw. 2010; 36:1-46. https://doi. org/10.18637/jss.v036.i03.

15. Musunuru HB, Quon H, Davidson M, Cheung P, Zhang L, D’Alimonte L, Deabreu A, Mamedov A, Loblaw A. Dose-escalation of five-fraction SABR in prostate cancer: toxicity comparison of two prospective trials. Radiother Oncol. 2016; 118:112-17. https://doi.org/10.1016/j. radonc.2015.12.020. [PubMed]

16. Quon HC, Musunuru HB, Cheung P, Pang G, Mamedov A, D'Alimonte L, Deabreu A, Zhang L, Loblaw A. DoseEscalated Stereotactic Body Radiation Therapy for Prostate Cancer: Quality-of-Life Comparison of Two Prospective Trials. Front Oncol. 2016; 6:185. https://doi.org/10.3389/ fonc.2016.00185. [PubMed]

17. Helou J, D'Alimonte L, Quon H, Deabreu A, Commisso K, Cheung P, Chu W, Mamedov A, Davidson M, Ravi A, Loblaw A. Stereotactic ablative radiotherapy in the treatment of low and intermediate risk prostate cancer: is there an optimal dose? Radiother Oncol. 2017; 123:478-82. https://doi.org/10.1016/j.radonc.2017.03.006. [PubMed]

18. Johnson SB, Soulos PR, Shafman TD, Mantz CA, Dosoretz AP, Ross R, Finkelstein SE, Collins SP, Suy S, Brower JV, Ritter MA, King CR, Kupelian PA, et al. Patient-reported quality of life after stereotactic body radiation therapy versus moderate hypofractionation for clinically localized prostate cancer. Radiother Oncol. 2016; 121:294-98. https://doi.org/10.1016/j.radonc.2016.10.013. [PubMed]

19. King CR, Collins S, Fuller D, Wang PC, Kupelian P, Steinberg M, Katz A. Health-related quality of life after stereotactic body radiation therapy for localized prostate cancer: results from a multi-institutional consortium of prospective trials. Int J Radiat Oncol Biol Phys. 2013; 87:939-45. https://doi.org/10.1016/j.ijrobp.2013.08.019. [PubMed]

20. King CR, Freeman D, Kaplan I, Fuller D, Bolzicco G, Collins S, Meier R, Wang J, Kupelian P, Steinberg M, Katz A. Stereotactic body radiotherapy for localized prostate cancer: pooled analysis from a multi-institutional consortium of prospective phase II trials. Radiother Oncol. 2013; 109:217-21. https://doi.org/10.1016/j. radonc.2013.08.030. [PubMed]

21. Kotecha R, Djemil T, Tendulkar RD, Reddy CA, Thousand RA, Vassil A, Stovsky M, Berglund RK, Klein EA, Stephans KL. Dose-Escalated Stereotactic Body Radiation Therapy for Patients With Intermediate- and High-Risk Prostate Cancer: Initial Dosimetry Analysis and Patient Outcomes. Int J Radiat Oncol Biol Phys. 2016; 95:960-64. https://doi.org/10.1016/j.ijrobp.2016.02.009. [PubMed]

22. Kim DW, Straka C, Cho LC, Timmerman RD. Stereotactic Body Radiation Therapy for Prostate Cancer: Review of Experience of a Multicenter Phase I/II Dose-Escalation
Study. Front Oncol. 2014; 4:319. https://doi.org/10.3389/ fonc.2014.00319. [PubMed]

23. Boike TP, Lotan Y, Cho LC, Brindle J, DeRose P, Xie XJ, Yan J, Foster R, Pistenmaa D, Perkins A, Cooley S, Timmerman R. Phase I dose-escalation study of stereotactic body radiation therapy for low- and intermediate-risk prostate cancer. J Clin Oncol. 2011; 29:2020-26. https:// doi.org/10.1200/JCO.2010.31.4377. [PubMed]

24. Macias VA, Blanco ML, Barrera I, Garcia R. A Phase II Study of Stereotactic Body Radiation Therapy for LowIntermediate-High-Risk Prostate Cancer Using Helical Tomotherapy: Dose-Volumetric Parameters Predicting Early Toxicity. Front Oncol. 2014; 4:336. https://doi.org/10.3389/ fonc.2014.00336. [PubMed]

25. Bernetich M, Oliai C, Lanciano R, Hanlon A, Lamond J, Arrigo S, Yang J, Good M, Feng J, Brown R, Garber B, Mooreville M, Brady LW. SBRT for the Primary Treatment of Localized Prostate Cancer: The Effect of Gleason Score, Dose and Heterogeneity of Intermediate Risk on Outcome Utilizing 2.2014 NCCN Risk Stratification Guidelines. Front Oncol. 2014; 4:312. https://doi.org/10.3389/fonc.2014.00312. [PubMed]

26. Bauman G, Ferguson M, Lock M, Chen J, Ahmad B, Venkatesan VM, Sexton T, D'Souza D, Loblaw A, Warner A, Rodrigues G. A Phase 1/2 Trial of Brief Androgen Suppression and Stereotactic Radiation Therapy (FASTR) for High-Risk Prostate Cancer. Int J Radiat Oncol Biol Phys. 2015; 92:856-62. https://doi.org/10.1016/j. ijrobp.2015.02.046. [PubMed]

27. D'Agostino G, Franzese C, De Rose F, Franceschini D, Comito T, Villa E, Alongi F, Liardo R, Tomatis S, Navarria P, Mancosu P, Reggiori G, Cozzi L, Scorsetti M. High-quality Linac-based Stereotactic Body Radiation Therapy with Flattening Filter Free Beams and Volumetric Modulated Arc Therapy for Low-Intermediate Risk Prostate Cancer. A Mono-institutional Experience with 90 Patients. Clin Oncol (R Coll Radiol). 2016; 28:e173-78. https://doi. org/10.1016/j.clon.2016.06.013. [PubMed]

28. Shikama N, Kumazaki Y, Miyazawa K, Nihei K, Hashimoto S, Tsukamoto N. Rectal Toxicity After Extremely Hypofractionated Radiotherapy Using a Non-Isocentric Robotic Radiosurgery System for Early Stage Prostate Cancer. World J Oncol. 2016; 7:98-103. https://doi. org/10.14740/wjon986w. [PubMed]

29. Rucinska M, Kieszkowska-Grudny A, Nawrocki S. SHARP hypofractionated stereotactic radiotherapy is well tolerated in prostate cancer: toxicity and quality of life assessment. Strahlenther Onkol. 2016; 192:449-57. https://doi. org/10.1007/s00066-016-0971-2. [PubMed]

30. Hannan R, Tumati V, Xie XJ, Cho LC, Kavanagh BD, Brindle J, Raben D, Nanda A, Cooley S, Kim DW, Pistenmaa D, Lotan Y, Timmerman R. Stereotactic body radiation therapy for low and intermediate risk prostate cancer-Results from a multi-institutional clinical trial. Eur J Cancer. 2016; 59:142-51. https://doi.org/10.1016/j. ejca.2016.02.014. [PubMed] 
31. Meier R, Beckman A, Henning G, Mohideen N, Woodhouse SA, Cotrutz C, Kaplan ID. Five-Year Outcomes From a Multicenter Trial of Stereotactic Body Radiation Therapy for Low- and Intermediate-Risk Prostate Cancer. Int J Radiat Oncol Biol Phys. 2016; 96:S33-S34. https://doi. org/10.1016/j.ijrobp.2016.06.094.

32. Boyer MJ, Papagikos MA, Kiteley R, Vujaskovic Z, Wu J, Lee WR. Toxicity and quality of life report of a phase II study of stereotactic body radiotherapy (SBRT) for low and intermediate risk prostate cancer. Radiat Oncol. 2017; 12:14. https://doi.org/10.1186/s13014-016-0758-8. [PubMed]

33. Zietman AL, Bae K, Slater JD, Shipley WU, Efstathiou JA, Coen JJ, Bush DA, Lunt M, Spiegel DY, Skowronski R, Jabola BR, Rossi CJ. Randomized trial comparing conventional-dose with high-dose conformal radiation therapy in early-stage adenocarcinoma of the prostate: longterm results from proton radiation oncology group/american college of radiology 95-09. J Clin Oncol. 2010; 28:1106-11. https://doi.org/10.1200/JCO.2009.25.8475. [PubMed]

34. Kuban DA, Tucker SL, Dong L, Starkschall G, Huang EH, Cheung MR, Lee AK, Pollack A. Long-term results of the M. D. Anderson randomized dose-escalation trial for prostate cancer. Int J Radiat Oncol Biol Phys. 2008; 70:6774. https://doi.org/10.1016/j.ijrobp.2007.06.054. [PubMed]

35. Hamstra DA, Mariados N, Sylvester J, Shah D, Karsh L, Hudes R, Beyer D, Kurtzman S, Bogart J, Hsi RA, Kos M, Ellis R, Logsdon M, et al. Continued Benefit to Rectal Separation for Prostate Radiation Therapy: Final Results of a Phase III Trial. Int J Radiat Oncol Biol Phys. 2017; 97:976-85. https://doi.org/10.1016/j.ijrobp.2016.12.024.
36. King CR, Brooks JD, Gill H, Presti JC Jr. Long-term outcomes from a prospective trial of stereotactic body radiotherapy for low-risk prostate cancer. Int J Radiat Oncol Biol Phys. 2012; 82:877-82. https://doi.org/10.1016/j. ijrobp.2010.11.054. [PubMed]

37. Widmark A, Gunnlaugsson A, Beckman L, ThellenbergKarlsson C, Hoyer M, Lagerlund M, Fransson P, Kindblom J, Ginman C, Johansson B, Seke M, Björnlinger K, Kjellén E, et al. Extreme Hypofractionation versus Conventionally Fractionated Radiotherapy for Intermediate Risk Prostate Cancer: Early Toxicity Results from the Scandinavian Randomized Phase III Trial "HYPO-RT-PC". Int J Radiat Oncol Biol Phys. 2016; 96:938-9. https://doi.org/10.1016/j. ijrobp.2016.09.049.

38. Yoshida K, Yamazaki H, Nakamara S, Masui K, Kotsuma T, Akiyama H, Tanaka E, Yoshioka Y. Comparison of common terminology criteria for adverse events v3.0 and radiation therapy oncology group toxicity score system after high-dose-rate interstitial brachytherapy as monotherapy for prostate cancer. Anticancer Res. 2014; 34:2015-18. [PubMed]

39. Aizer AA, Anderson NS, Oh SC, Yu JB, McKeon AM, Decker RH, Peschel RE. The impact of pretreatment prostate volume on severe acute genitourinary toxicity in prostate cancer patients treated with intensity-modulated radiation therapy. Int J Radiat Oncol Biol Phys. 2011; 79:379-84. https://doi.org/10.1016/j.ijrobp.2009.11.023. [PubMed] 